\title{
First finding of Kelleromyxa fimicola in the Republic of Buryatia (Eastern Siberia)
}

\section{Vlasenko AV and Dulepova NA}

Central Siberian Botanical Garden, Siberian Branch of the Russian Academy of Sciences, Zolotodolinskaya, 101, Novosibirsk 630090, Russia

Vlasenko AV, Dulepova NA 2015 - First finding of Kelleromyxa fimicola in the Republic of Buryatia (Eastern Siberia). Current Research in Environmental \& Applied Mycology 5(2), 149152, Doi 10.5943/cream/5/2/9

\begin{abstract}
For the first time in Eastern Siberia the research has revealed a rare species of coprophilous myxomycetes - Kelleromyxa fimicola. Specimens were obtained from horse dung in a moist chamber culture.
\end{abstract}

Key words - myxomycetes - moist chamber culture - dung - microorganisms

\section{Introduction}

The purpose of the study is to examine the distribution of an unknown species of myxomycete in Eastern Siberia.

K. fimicola relates to a monotypic genus Kelleromyxa Eliasson. Based on the resemblance of its sporocarps to those of Licea biforis Morgan, the species was first described as Licea fimicola Dearn. et Bisby and placed within the Liceales. Modern morphological (Eliasson et al. 1991) and phylogenetic (Erastova et al. 2013) studies showed that Kelleromyxa may have affinities with the order Physarales.

$K$. fimicola is found in arid habitats on dung of cattle and is one of the few obligate coprophilic species among myxomycetes. Uno Eliasson (2012) noted that K. fimicola has a dense peridium of the sporocarp and thick-walled spores that can serve as an special mechanism to pass through the digestive tract of herbivores and subsequent germination of spores on dung.

The genus was earlier found in Canada, USA, Mexico, Kenya, China and Kazakhstan. In Russia K. fimicola was observed in Nizhnee Povolzhe 48 $22^{\prime} 30^{\prime} \mathrm{N} 46^{\circ} 25^{\prime} 60^{\prime \prime} \mathrm{E}$ (Zemlyanskaya 2003), the Urals (Fefelov 2009, geographical reference does not exist in this the paper) and the

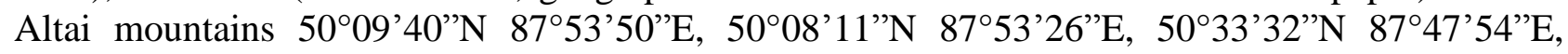
$50^{\circ} 10^{\prime} 27^{\prime} \mathrm{N} 87^{\circ} 54^{\prime} 00^{\prime} \mathrm{E}, 50^{\circ} 36^{\prime} 43^{\prime} \mathrm{N}$ 86¹8'50’'E (Novozhilov et al. 2009, 2010).

\section{Materials \& Methods}

The survey for myxomycetes from steppe and sandy landscapes in Zabaykalya (the Republic of Buryatia and Zabaykalsky krai) started in 2011. The substrates to reveal myxomycetes were obtained by applying the moist chamber culture technique in the lower part of the basin of the Selenga river - in the intermontane depressions and directed to them windward slopes of low mountains (Malkhanskiy, Zaganskiy, Tsagan-Daban, Borgoyskiy ridges), in Barguzinskaya and 
Verkhnecharskaya basins along the eastern coast of Lake Baikal and it's north end (the islands Yarki and Millionnyy, Dagarskaya guba), as well as in the middle part of the basin of the Onon and Uldza rivers. The following types of substrates were selected: the lower part of the living and dead dwarf semishrub, dry grass waste, and dung of various herbivores.

Specimens of each substrate for moist chamber were collected from one microhabitat and placed into standard Petri dishes. Cultures were kept at room temperature $\left(20-25^{\circ} \mathrm{C}\right)$ and scattered light within 100 days, and checked eight times under a binocular loupe. After 81 days of cultivation several thousand sporocarps of $K$. fimicola were observed on horse dung. Horse dung for moist chambers was collected on a sandy massif located $8.5 \mathrm{~km}$ south-west from the village Enkhor, Selenginskiy region the Republic of Buryatia, 5058'26.544'N 106 22'58.512'E; height 557, exposure 151, slope $7-6^{\circ}$, a sand ridge, herb-elm community (Herbo variae-Ulmus pumila).

Spores were studied using light (Carl Zeiss Axioskop-40) and scanning electron (Carl Zeiss Merlin FC-SEM) microscopy.

\section{Results \\ Kelleromyxa fimicola (Dearn et Bisby) Eliasson, 1991, Mycological Research 95: 1206.}

$\equiv$ Licea fimicola Dearn. et Bisby, 1929, The fungi of Manitoba: 52 .

Sporocarps scattered, gregarious or clustered, on cattle dung. Immature sporangia have a dark reddish-purple sporothecae which becomes black and shiny as it matures. Sporothecae varies from spindle-shaped to oval and pillow-shaped. Sporocarp height to $0.7 \mathrm{~mm}$, width $0.05-0.25 \mathrm{~mm}$. Peridium is dense, cartilaginous, black, brown in transmitted light. Dehiscence by separation of the two sides along what appears to be a preformed suture, or occasionally irregular. Spore-mass is dark brown, light brown in transmitted light. Spores are 15-20 microns diam., spherical, collected into complexes (clustered) from 9 to 50 units. Ornamented with straight and sometimes hookshaped spines up to $3 \mu \mathrm{m}$. Ornamentation is irregular, sometimes reticular, often one or more sides are smooth This is description has been made by the authors of this paper-based sporocarps obtained by culturing in a moist chamber culture technique.

\section{Discussion}

Identified samples differed somewhat from the previously described by ornamentation and size of the spores. The specimens obtained from East Siberia have spores up to $20 \mu \mathrm{m}$ diam., assembled into complexes, ornamented with aciculae up to $3 \mu \mathrm{m}$, whereas the previously identified spores 11 (13)-15 (16) are ornamented with aciculae up to 1-1.2 $\mu \mathrm{m}$ (Zemlyanskaya 2003, Martin \& Alexopoulos 1969, Erastova et al. 2013).

The moist chamber culture technique was first described by Martin and Gilbert (Gilbert \& Martin 1933). It is based on the presence of a resting stage in the life cycles of slime molds (the socalled microcysts) from which plasmodia may develop under favorable conditions.

The moist chamber culture technique is widely used in study of myxomycetes diversity in the desert and steppe communities where sometimes it is the only possible way to identify species diversity of slime molds, which is connected with the biology of myxomycetes. When culturing, the samples of substrates were placed on sterile pieces of paper in laboratory Petri dishes which filled onto a $1 / 3$ with distilled water, capped, and left at room temperature for a day. The following day, the $\mathrm{pH}$ of the water was determined with a $\mathrm{pH}$ meter, and most of the water remaining in the plate was poured out. Samples were maintained under ambient conditions and diffuse light from 1.5 to 2-3 months. A small amount of water was added to any culture that seemed to be drying out.

During the experiments on cultivation of slime mold in moist chambers in the laboratory humidity, moisture duration, nature of light and temperature conditions may not correspond to the natural conditions in which the transition from the vegetative stage (plasmodium) to generative stage (sporocarp) occurs. The mismatch of conditions often leads to the formation of atypical sporothecae, stalk reduction, capillitium underdevelopment, uncharacteristic lime incrustation, 


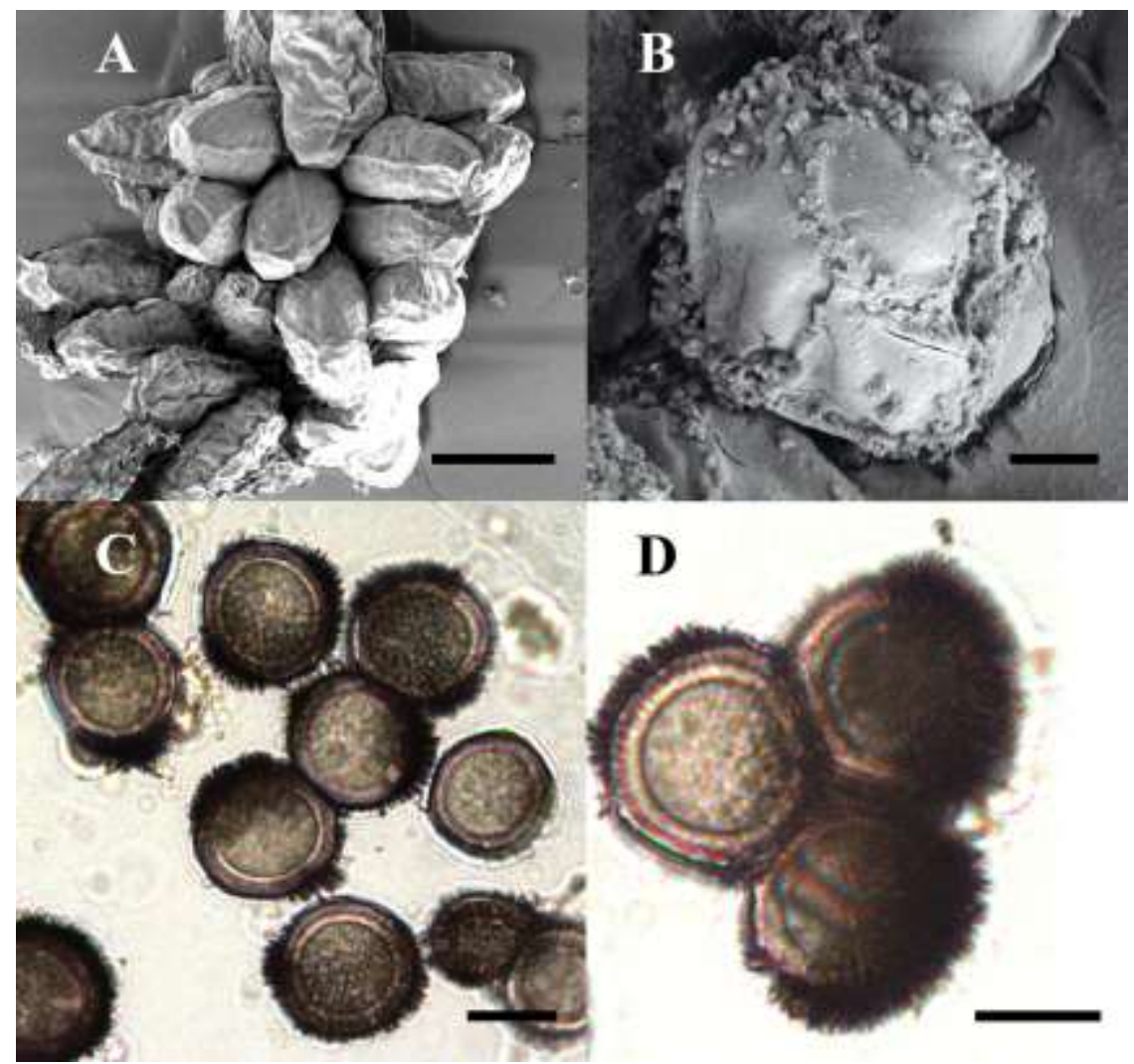

Fig. 1 - A-D Kelleromyxa fimicola A Sporocarps under SEM microscopy - Bar $=200 \mu \mathrm{m}$. B Spore under SEM microscopy - Bar $=3 \mu \mathrm{m}$. C Spores under light microscopy - Bar $=10 \mu \mathrm{m}$. D Spores under light microscopy $-\mathrm{Bar}=10 \mu \mathrm{m}$.

increase in the spores diameter that may be erroneously interpreted as a stable morphological characters and the following description of a new taxon.

Thus, we believe that the differences in size and ornamentation of spores in samples of $K$. fimicola, obtained from Republic of Buryatia cannot serve as evidence for description of a new taxon.

\section{Acknowledgements}

This work was financed by the grant RFBR № 14-04-01408A.

\section{References}

Eliasson UH, Keller HW, Schoknecht JD. 1991 - Kelleromyxa, a new generic name for Licea fimicola (Myxomycetes). Mycological Research 95, 1201-1207.

Eliasson U. 2012 - Coprophilous Myxomycetes: Recent advances and future research directions. Fungal Diversity 59 (1), 85-90.

Erastova DA, Okun MV, Fiore-Donno AM, Novozhilov YK, Schnittler M. 2013 - Phylogenetic position of the enigmatic myxomycete genus Kelleromyxa revealed by SSU rDNA sequences. Mycological Progress 12(3), 599-608.

Fefelov KA. 2009 - Comparison of the complexes myxomycetes of Ural steppes. Vestnik OGU 6, 387-389. (in Russian).

Gilbert HC, Martin GW. 1933 - Myxomycetes found on the bark of living trees. Iowa University. Studies in Natural History 15(3), 3-8.

Martin GW, Alexopoulos CJ. 1969 - The Myxomycetes. The University of Iowa Press, Iowa City. 
Novozhilov YK, Schnittler M, Vlasenko AV, Fefelov KA. 2009 - Myxomycete diversity of the Chuyskaya depression (Altay, Russia). Micologiya i fitopatologiya 43(6), 522-534. (in Russian).

Novozhilov YK, Schnittler M, Vlasenko AV, Fefelov KA. 2010 - Myxomycete diversity of the Altay Mts. (southwestern Siberia, Russia). Mycotaxon 111, 91-94.

Zemlyanskaya IV. 2003 - Myxomycetes steppes and deserts of the Lower Volga region. Diss. cand. biol. Sciences. Volgograd-St. Petersburg. 